\title{
A hipótese do progresso do conceito e a Ciência da Informação
}

\section{The hypothesis of the progress of concept and Information Science}

Marivalde Moacir FRANCELIN'

\section{Resumo}

Este artigo analisa relações contrastantes dos conceitos na filosofia e na ciência, discutindo as noções de progresso e paradigma. Levanta a hipótese de que os conceitos estão vinculados em todas as ordens tradicionais de explicação. Nessa perspectiva, os conceitos podem ser apresentados e representados, concomitantemente, no plano das ideias e da linguagem. A pesquisa foi realizada com base em revisão bibliográfica, utilizando o método de bricolagem para relacionar teorias distintas. Indica potenciais diferenças e limites epistemológicos na análise do progresso no contexto paradigmático do conceito científico e filosófico. Assim, coloca em discussão a hipótese do progresso do conceito e a noção de progresso adotada para o conceito-objeto informação na Ciência da Informação. Primeiramente, apresenta uma visão panorâmica dos conceitos na filosofia. Na sequência, levanta a questão do progresso dos conceitos e sua relação com a linguagem e os paradigmas. Conclui que a noção de paradigma, apesar de impactar nas abordagens filosófica e científica da informação, pode estar deslocada do campo epistemológico.

Palavras-chave: Ciência da informação. Conceito. Epistemologia. Linguagem. Paradigma.

\begin{abstract}
The aim of the article is to analyze the contrasting relationships of concepts in philosophy and science and discuss the notions of progress and paradigm. We raise the hypothesis that concepts are connected to all traditional explanations. In this perspective, the concepts can be presented and represented, concomitantly, in the level of ideas and language. Based on a bibliographic review, we use the bricolage method for relating different theories. We indicate potential differences and epistemological limits in the analysis of progress in the paradigmatic context of the scientific and philosophical concept. Thus, we discuss the hypotheses of progress of concepts and notion of progress adopted for the concept-object of information in Information Science. First, we present a panoramic view of the concepts in philosophy. Next we raise the question of the progress of concepts and their relationship to language and paradigms. It may be concluded that the notion of paradigm, although it impacts the philosophical and scientific approaches of information, can be displaced from the epistemological field.
\end{abstract}

Keywords: Information science. Concepts. Epistemology. Language. Paradigm.

\section{Introdução}

Este artigo analisa a hipótese do progresso do conceito filosófico e científico e seus desdobramentos na Ciência da Informação. A hipótese do progresso do conceito filosófico e científico sugere duas questões que podem ser relacionadas ao conceito-objeto informação. Isto é: existe a possibilidade de pensar o progresso científico de uma área de conhecimento através da análise de seus conceitos? Seria possível analisar o

1 Universidade de São Paulo, Escola de Comunicações e Artes, Departamento de Biblioteconomia e Documentação. Av. Prof. Lúcio Martins Rodrigues, 443, 05508-020, Cidade Universitária, São Paulo, SP, Brasil.E-mail:<marivalde@usp.br>.

Recebido em 14/5/2013, reapresentado em 16/5/2014 e aceito para publicação em 18/8/2014. 
progresso dos conceitos filosóficos assim como o progresso dos conceitos científicos e, dessa forma, pensar também na possibilidade de religação da ciência e da filosofia para uma análise epistemológica do conceito-objeto informação?

$\mathrm{Na}$ abordagem dessas questões, são apresentados contrastes na relação dos conceitos com a filosofia, com a ciência e com a linguagem. Os contrastes mostrados estão nas facetas que podem ser encontradas quando se fala de conceitos em campos aparentemente divergentes, como o das ideias e dos usos, do determinismo e do indeterminismo, dos fatos e dos discursos, especialmente na definição de paradigmas e na avaliação do progresso do conhecimento na ciência e na filosofia.

\section{Procedimentos metodológicos}

Foram usados os métodos de revisão bibliográfica e de bricolagem. A revisão bibliográfica baseou-se no critério de demonstração para as abordagens filosóficas do conceito e no critério de seleção para a análise do progresso dos conceitos na ciência e na linguagem. Os dois critérios usados na revisão têm como função direcionar, metodologicamente, abordagens referenciais dos conceitos na tradição filosófica para pontos específicos nas abordagens científicas dos conceitos. Esse direcionamento fundamentou a discussão sobre a hipótese do progresso do conceito, onde teoria e descrição são analisadas a partir dos pontos de vista de Wittgenstein (1989, 2001) e de Kuhn $(1989,2001,2006)$.

Para estabelecer, na revisão bibliográfica, um princípio epistemológico com base na relação de discursos e conceitos aparentemente distintos, foi usado o método de bricolagem. Uma das aplicações da bricolagem encontra-se nos estudos culturais de Lévi-Strauss, também pode ser encontrada em Jacques Derrida, Michel de Certeau e em Edgar Morin. Além da busca de sentidos em discursos distintos e até conflitantes, a bricolagem permite o exercício epistemológico de remapeamento de alguns conceitos, levando em consideração sujeitos e objetos em contextos que vão além das análises sobre a possibilidade de conhecimento científico.

Os tópicos seguintes, portanto, colocam em destaque a questão da linguagem nos campos científico, conceitual e paradigmático, introduzindo a discussão da noção de progresso sobre o conceito-objeto informação.

\section{Contra-análise filosófica: síntese panorâmica e de referência dos conceitos}

A primeira questão observada nos manuais de referência de filosofia é a dificuldade de compreender a dimensão do conceito. Ferrater Mora (2004), no Dicionário de Filosofia, lembra que o termo conceito foi definido de diversas maneiras, levando a aproximações com termos, que também tiveram usos variados, como os de noção, de ideia e de pensamento. Tais aproximações, na visão de Ferrater Mora (2004), não foram de muita ajuda na compreensão do significado do termo conceito.

Outra dificuldade indicada nesses manuais refere-se ao próprio uso do termo conceito. Ele é usado de maneira vaga e generalizada em diversos contextos e situações. Para contornar o problema, Ferrater Mora (2004) defende a necessidade de precisão dos referenciais quando deslocados de seus contextos históricos e teóricos. Para exemplificar, Ferrater Mora (2004) fala da tradução insatisfatória do termo grego logos por conceito. Abbagnano (2007, p.194) também apresenta o termo "conceito" em outras línguas (conceptus, concept, concetto, Begriff), porém o primeiro termo elencado como representante do conceito é o $\lambda$ óyos (logos) grego, o que apresenta uma aparente contradição com Ferrater Mora (2004).

Evitando uma polêmica terminológica, verifica-se que Abbagnano (2007) concorda com a ideia de generalidade do conceito, podendo incluir qualquer processo semântico ou sinal. Embora um conceito possa ser nomeado, ele não é o nome. Um mesmo conceito pode ser expresso por diversos significantes ou ter diversos significados, isto é, um conceito pode ter diversos nomes ou um nome pode exprimir diversos conceitos. O conceito apresenta outras complexidades relacionadas às teorias que pretende representar, como é caso do conceito de relatividade e do conceito de evolução nas ciências naturais e nas ciências humanas. $O$ conceito também não se refere exclusivamente às coisas existentes ou aos fatos que podem ser verificados na realidade, pelo contrário, é possível encontrar o conceito 
vinculado a coisas que não podem ser comprovadas por fatos da realidade e não possuem um sentido determinado. Para Abbagnano (2007, p.195), a provável existência de alguma universalidade subjetiva ou de alguma validade intersubjetiva do conceito resume-se, na realidade, à sua capacidade de comunicação como "signo linguístico", ou seja, a função do conceito seria a mesma da linguagem.

Os conceitos, na divisão proposta por Ferrater Mora (2004), são considerados convencionais e instrumentais; iguais a significados; como descrições econômicas para as operações classificatórias e definitórias; em oposição às interpretações nominalistas e empiristas; distinguidos entre realidade psicológica e validade lógica. Os conceitos também podem ser distintos: de objetos; de preceitos, mas considerados como algo percebido; e separados em conceitos semântios e absolutos ou ligados ao idealismo hegeliano como elementos"últimos de todos os pensamentos" (Ferrater Mora, 2004, p.520). Os conceitos podem, ainda, apresentar diferentes características, tais como compreensão e extensão. Também podem ser classificados em objetivos e funcionais de acordo com a lógica, e, de acordo com a ontologia, serem subordinados e coordenados. Existem os conceitos que podem ser considerados gerais, como os de gênero e espécie, os conceitos "gerais em outro sentido", como os plurais, os universais, os coletivos e, ainda, os conceitos abstratos e concretos e os simples e compostos.

Em resumo, os conceitos podem ser produtos do espírito, representantes de fatos verificáveis na realidade, construtos mentais e expressões significantes que acontecem no uso da linguagem. As abordagens indicadas acima são representações parciais das teorias dedicadas ao estudo dos conceitos nas discussões filosóficas, no aprimoramento das teorias científicas e na função assumida pela linguagem nos estudos sobre o conhecimento na contemporaneidade. Nenhuma teoria ou análise é capaz de sistematizar as diversas formas que filósofos e cientistas usaram e usam o termo conceito. Por outro lado, é possível levantar a hipótese de que quase todos eles usaram ou usam o termo conceito em contextos baseados em fatos da realidade ou fundamentados no campo da representação, numa aparente oposição entre imediato e mediato em sentidos pragmático e cognitivo. Um desses contextos é o da linguagem, mas ela também incorpora os dois sentidos, distribuindo- -os em padrões teóricos e conceituais na ciência e em concepções e ações na filosofia.

\section{Sobre os modos de produção e o progresso dos conceitos na ciência}

Na ciência, os conceitos são importantes porque definem objetos, fenômenos e acontecimentos e as relações existentes entre eles, a natureza e a sociedade. A caracterização dos conceitos na ciência supõe o uso da linguagem dentro de limites definidos e sem ambiguidades. Na ciência, os conceitos criados intencionalmente, com significados específicos e que podem ser "operados" chamam-se, segundo Köche (2002) construtos. Outro ponto que pode ser destacado é a diferença entre noção, ideia e conceito. Para Fourez (1995), noção implica algo vago e individual. Uma pessoa tem a noção de algo, tem uma vaga compreensão do que significa uma família, por exemplo. A ideia estaria ligada a algo coletivo e geral, "universal”. A ideia de natureza e de Deus, por exemplo. O conceito é uma noção quase precisa, desenvolvida dentro de algum paradigma. Por exemplo, o conceito de família na Sociologia, de natureza na Biologia e de Deus na Antropologia ou na Teologia. Assim, Köche (2002, p.115) diz que a linguagem científica "[...] deve ser específica e delimitada. Ela tenta representar a realidade através de uma simbologia que deverá ser o máximo exata, sensível e consensual (intersubjetiva) e representar o mais exatamente possível os fenômenos da realidade".

A linguagem natural era a linguagem da ciência nos períodos grego e medieval. Esse modo de produção de conceitos foi substituído com a ciência moderna. 0 conhecimento ocidental tem sua forma inicial traçada pela mitologia grega. Símbolos e metáforas eram usados para explicar as coisas da natureza e do homem. A racionalidade moderna substitui símbolos e metáforas pelo conceito. O conceito é caracterizado por um tipo de circularidade ausente nas metáforas mitológicas. De acordo com Gil (1979, p.166), a "[...] ciência moderna forma-se pela derrocada do modo 'grego' de produção dos conceitos [...]". Nessa ótica, afirma o autor, "O modo de produção da ciência é em primeiro lugar um modo de produção de conceitos [...]" (Gil, 1979, p.165, grifo do autor). Constituindo-se circularmente, os conceitos 
na ciência são apresentados de maneira determinada e fixa.

A ideia de determinismo e fixação de posições na ciência pode ser necessária em alguns momentos para a própria demarcação de objetos e teorias científicas, mas também pode sofrer críticas e oposições quando fundamentada em postulados dogmáticos presos ao sentido dado à ciência como única forma de conhecimento verdadeiro e universal. É um equívoco afirmar que os conceitos científicos são fixos, universais e verdadeiros, pois a própria ciência, diante dos paradigmas contemporâneos de validade provisória e contextual, parece não mais aceitar tais postulados. A ciência também parece entender que seu desenvolvimento e de seus conceitos não acontece linearmente, pois sua construção é realizada por descobertas que nem sempre são as planejadas e desejadas, e o amadurecimento de suas teorias e conceitos depende de fatores variados e complexos.

Afirmando que a ciência não está atrelada a pontos fixos, Bachelard (1978), no livro A Filosofia do Não, faz a análise epistemológica do conceito científico em diversas perspectivas. Em uma delas, Bachelard (1978, p.11) dizque

É evidente que os conceitos científicos não atingiram todos o mesmo estádio de maturidade; muitos permanecem ainda implicados num realismo mais ou menos ingênuo; muitos são ainda definidos na orgulhosa modéstia do positivismo; o que faz com que, examinada nos seus elementos, a filosofia do espírito científico não possa ser uma filosofia homogênea.

Pode-se lembrar, aqui, por analogia, o conceito de informação na Ciência da Informação, muitas vezes discutido na tentativa de dimensionar e consolidar um objeto de pesquisa da área. Outras vezes, a própria maturidade científica da Ciência da Informação foi questionada devido à dinâmica e heterogeneidade do conceito e das formas de apresentação e análise do objeto. O conceito de informação é analisado e discutido na Ciência da Informação, pois representa, de certa maneira, um "termômetro" na avaliação do progresso científico da área.

Segundo Bachelard (1978), é mais importante para a ciência analisar o progresso dos conceitos científicos do que a filosofia analisar o progresso dos conceitos filosóficos. De acordo com autor o conceito de progresso filosófico
É um conceito que tem pouco significado em filosofia pura. Não caberia na cabeça de nenhum filósofo dizer que Leibniz estava adiantado em relação a Descartes, Kant adiantado em relação a Platão. Mas o sentido da evolução filosófica dos conceitos científicos é tão claro que se torna necessário concluir que o conhecimento científico ordena a própria filosofia. O pensamento científico fornece, pois, um princípio para a classificação das filosofias e para o estudo do progresso da razão (Bachelard, 1978, p.12).

Não é possível, no momento, adotar a posição de Bachelard para o progresso dos conceitos na Ciência da Informação, em especial para o conceito de informação. Como mencionado, o conceito de informação na Ciência da Informação passa por diversas análises, discussões e debates que evidenciam posições favoráveis ou não a determinadas vertentes, ou seja, o conceito de informação é constantemente "dialetizado"e o seu conteúdo é revisado a partir de opiniões diferentes. Por outro lado, à perspectiva filosófica relacionam-se níveis e contextos de significados do conceito de informação, contrários, por sua vez, à exatidão requerida para o conceito científico. Esse requerimento científico e o perspectivismo filosófico não impedem a discussão e o debate epistemológico do conceito de informação. Na evidência das oposições, existe a "surpresa" do diálogo. Nesse sentido, Bachelard desconfia dos conceitos que não sofreram discussões, que não foram "dialetizados".

Dever-se-ia, pois, desconfiar sempre de um conceito que não tivesse ainda sido dialetizado. 0 que impede a sua dialetização é uma sobrecarga do seu conteúdo. Esta sobrecarga impede o conceito de ser delicadamente sensível a todas as variações das condições em que ele assume as suas justas funções. Atribui-se seguramente demasiado significado a esse conceito, dado que nunca é pensado formalmente. Mas se se Ihe atribui demasiado significado, é de temer que dois espíritos diferentes não the atribuam o mesmo significado. Daqui resultam as profundas perturbações semânticas que impedem a compreensão recíproca dos homens do nosso tempo. Sofremos de uma incapacidade de mobilizar o nosso pensamento. Para termos alguma garantia de termos a mesma opinião acerca de uma ideia particular, é preciso pelo menos que tenhamos tido sobre ela opiniões diferentes. Se dois homens se querem entender verdadeiramente, têm pri- 
meiro que se contradizer. A verdade é filha da discussão e não filha da simpatia (Bachelard, 1978, p.81, grifo do autor).

Mesmo considerando que os conceitos passam por um processo "fisiológico", funcional e intencional, permitindo-lhes atingir "pontos fixos do pensamento", para Bachelard (2004), tais condições modificam-se no estudo de suas aplicações. De um ponto de vista epistemológico, pode-se dizer que Bachelard não vê, nas posições extremas de sínteses racionalistas, positivistas ou empiristas, nenhum fator vinculado à construção do conhecimento. As posições de Bachelard (2004), vão desde a crítica às definições, por considerar que elas nada demonstram e apenas servem para fixar uma linguagem, até o consentimento de que o conceito possui características suficientes para reconhecer um objeto, mas elas seriam o esforço mínimo diante da multiplicidade que poderia ser alcançada pelo conceito no "espírito".

O pensamento depende da capacidade de relacionar conceitos e, paradoxalmente, isolá-los. Também é possível dizer que tais relacionamentos (e isolamentos) acontecem no emprego e uso da linguagem. O deslocamento que pode ocorrer, nesse caso, está na importância dada à linguagem no universo das representações cognitivas e sociais e da ressignificação de conteúdos, implicando a sua relação com conceitos.

\section{Conceitos e seus lugares de passagem na linguagem}

A filosofia e as ciências dão grande importância para a linguagem, especialmente em sua relação com o conceito. Para Hjelmslev (2006, p.2) "A linguagem, como sistema de signos, devia fornecer a chave do sistema conceitual e a da natureza psíquica do homem". Bachelard (2004, p.28), por sua vez, afirma que "O pensamento só começa com a linguagem, é contemporâneo da junção dos conceitos". E, para Cassirer (2003, p.51), "[...] a linguagem nunca designa simplesmente os objetos como tais, mas sempre conceitos formados pela atividade espontânea do espírito [...]". De início, portanto, é possível observar que a linguagem ocupa lugar de destaque na natureza do pensamento humano, isto é, pode-se entender que a linguagem é elemento primordial na própria noção de construção de conhecimento.
O homem faz uso da linguagem para expressar o pensamento, cujo produto é o conhecimento. Ele conhece algo pela ação da linguagem. Para Tálamo (2004, online), é no plano da linguagem que coisas e ideias se agregam, ou seja,

[...] a produção de linguagem e a produção de conhecimento são processos associados reciprocamente. De modo preciso, considerando-se que a informação é troca com o mundo e o conhecimento sua apropriação, organização e articulação, tem-se que a produção da linguagem e a produção do conhecimento são processos solidários que mantêm relação de pressuposição recíproca.

Cintra et al. (2002, p.26) destacam que a linguagem passou a ser"[...] tomada como chave de acesso do homem moderno às leis do funcionamento social [...]" depois de constituir-se em um objeto científico. Considerando, portanto, a linguagem no "funcionamento social" não é possível colocá-la, unicamente, em relação de dependência com o pensamento num sentido cognitivo restrito. Os conceitos produzidos na linguagem necessitam de um universo representacional onde possam ser transmitidos, significados e ressignificados.

A Ciência da Informação vem promovendo estudos sistemáticos sobre a linguagem, suscitados pelo interesse nos processos de tratamento e mediação da informação. A semântica e a pragmática, como também o estruturalismo, estão na base de muitos estudos sobre a linguagem. Entretanto, devido à proliferação de estudos sobre a linguagem nos últimos anos, fica difícil estabelecer referenciais teóricos precisos. Tal proliferação se fundamenta em um fecundo mosaico teórico, que vai de Saussure a Apel, passando por Wittgenstein, Peirce, Quine, Foucault, Bakhtin, Searle e Chomsky. Se há preocupação com o tratamento e a mediação da informação e com seu uso em sociedade, os estudos sobre a linguagem são passagem obrigatória.

Falar de mediação e uso da informação em sociedade é falar também dos padrões de uso da linguagem em um ambiente epistêmico determinado no sentido de identidade sociocultural. Implica, ainda, entender os "mecanismos" de construção da linguagem e sua função no organismo social e epistêmico, incluindo tanto os grupos especializados quanto os não especializados, e as relações que os unem em redes discursivas 
de informação. Os processos discursivos são importantes, pois demandam acordos e contratos comunicacionais, além do conhecimento compartilhado das regras de uso da linguagem em torno de eixos paradigmáticos.

Numa relação historiográfica da filosofia, da ciência e da linguagem, Thomas Kuhn estabeleceu importantes analogias entre os discursos da ciência, os usos dos conceitos, os jogos de linguagem, as mudanças revolucionárias, a aprendizagem, os paradigmas e a incomensurabilidade. Na análise de González de Gómez (2005, p.19), Kuhn é um "pós-empiricista" que,

[...] atuando no campo da História das Ciências, em sincronia com a teoria dos jogos da linguagem de Wittgenstein, elabora o conceito de 'paradigma', no qual leva a suas últimas consequências os efeitos epistêmicos das especialidades, afirmando o caráter local e contextual dos discursos e práticas científicas. Para Kuhn, diferentes matrizes disciplinares agem como diferentes culturas ou subculturas, incomensuráveis em seus modos de olhar e de nomear suas objetivações construídas, de modo que não se poderia manter a diferenciação entre conceitos teóricos e conceitos empíricos. Entre um e outro paradigma ou entre um e outro jogo de linguagem não há tradução, mas 'conversão'.

Segundo González de Gómez (2004, p.63), a “[...] transferência da filosofia da linguagem do "segundo Wittgenstein" para os estudos da ciência levaria Kuhn a afirmar a impossibilidade de uma experiência neutra e a incomensurabilidade das linguagens e das teorias científicas". Kuhn $(1989,2001,2006)$, ao referir-se aos paradigmas, tinha em mente algo que realmente servisse de modelo (consenso) a partir de ciências reconhecidas universalmente.

No entanto, os paradigmas, apesar de serem únicos, são constituídos, apropriando-se de uma das características dada por Wittgenstein às semelhanças de família, de diversas"fibras". Seguindo a metáfora, é a variedade e, ao mesmo, a similaridade de características dessas fibras que permite a realização de ações coletivas e comunicativas dentro de um paradigma. Os chamados paradigmas dominantes não são totalitários ou dogmáticos. Ao contrário, são paradigmas que se destacam dentro das comunidades científicas, sendo aceitos e modificados por elas de acordo com uma terminologia consensual. No texto Aética da terminologia, Peirce (2005, p.39) diz que a"[...] trama de todo pensamento e de toda pesquisa são os símbolos, e que a vida do pensamento e da ciência é a vida inerente aos símbolos [...]", porém lembra que a linguagem é importante para o pensamento, constituindo uma essência e não uma totalidade. Peirce defende a liberdade de pensamento, "absoluta liberdade mental"em suas palavras, critica os chamados "pedantes" e "pedagogos" da comunidade científica e filosófica por tentarem impor uma "magistratura sobre os pensamentos e outros símbolos". Deve-se, diz Peirce, resistir à arbitrariedade nos assuntos científicos, principalmente com relação aos termos e notações, mas que um acordo racional entre "cooperadores" sobre o uso de termos e símbolos é indispensável para o progresso do pensamento.

\section{Discussão}

Os"campos de forças" paradigmáticos em atuação na Ciência da Informação estão em pleno processo de dialetização sobre a "legitimidade" epistemológica do conceito-objeto informação na perspectiva da teoria ou da experiência. Na situação problemática aqui proposta, a questão é saber, primeiro, onde começa a ciência e onde termina a filosofia, ou seja, onde começa a teoria e onde termina a descrição, e, segundo e mais importante, como esse limite pode ser interpretado quando se tenta analisar o progresso do conceito-objeto informação.

A hipótese para o primeiro problema defende que é impossível dividir teoria e descrição porque essa divisão só existiria, de fato, se ela fosse estabelecida, no momento da criação e da produção do conhecimento, pelo próprio criador ou produtor, isto é, se o próprio "autor", criador e produtor da teoria afirmasse que ela não o é de fato. Ele deveria demonstrar sua afirmação no próprio texto que agora seria seu "objeto" da experiência. Mesmo assim, ele poderia ser apresentado por seus intérpretes em outras perspectivas vinculadas aos campos da literatura, poesia, gramática, filologia, educação, política, filosofia e da ciência. Tudo depende das interpretações realizadas sobre pensamentos que marcaram épocas, foram combatidos, criticados, excluídos, ficaram escondidos ou perdidos, chegando ao período atual para desfrutarem a continuidade do esquecimento, a ascensão da polêmica ou a multiplicidade das análises e das sínteses. 
No segundo caso, a problemática sobre o conceito-objeto informação levanta uma hipótese complexa no sentido que parece unir filosofia e ciência. Seguindo a distinção wittgensteiniana, a filosofia não cria teorias, ela apenas procura tornar mais claros os problemas filosóficos através da descrição. Caberia, portanto, à ciência desenvolver teorias. Mas, se a primeira hipótese for verdadeira, ou seja, filosofia e ciência são indissociáveis numa perspectiva mais ampla do saber e do conhecimento, é possível também levantar a hipótese de que o objeto não está dissociado do conceito. Como entender um objeto que deve estar sempre em processo, algo como a própria linguagem? Por outro lado, não é possível imaginar uma informação sem sentido, mas seria possível imaginar algo que"signifique" por si mesmo. Se todos os conceitos em todas as áreas de conhecimento necessitam de sentidos para existir, seria também a informação elemento ou substância permanente em todos os objetos e conceitos? A discussão sobre o realismo e o idealismo não vem ao caso, pois é adotada uma visão fraca que os incorpora. Dessa perspectiva, o ponto de partida registra uma visão conjunta do que é e do que está.

Wittgenstein $(1989,2001)$ apresenta uma forma diferente de pensar os conceitos: em sua abordagem, a natureza e a origem do conceito, base dos estudos filosóficos sobre o conceito até então, são substituídos, por assim dizer, pelo emprego e pelo uso que se faz dos conceitos no campo da linguagem. Através do uso correto da linguagem propõe tornar nítidos os conceitos que estão na base das contradições, dos paradoxos e dos problemas filosóficos. Wittgenstein (2001), diz que a filosofia não é uma ciência como as ciências naturais. $O$ interesse sobre as causas da formação dos conceitos é das ciências naturais. A função da filosofia não é a mesma das outras ciências. A filosofia não desenvolve teorias, esta é a função da ciência. O papel da filosofia, de acordo com Wittgenstein (1989), é esclarecer problemas filosóficos através da descrição. Por meio de uma proposição, só é possível dizer como uma coisa é, mas não o que ela é.

Isto é assim e isto está assim. O que é está contido num conceito que, por sua vez, pode ter um nome. Em Wittgenstein (1989, 2001), o que está são fatos que, por sua vez, exprimem sentidos. Parece que, para esse filósofo, tanto no emprego das proposições, que projetam o mundo, como no emprego das palavras no cotidiano, os sentidos estão presos aos fatos expressos na linguagem. Isso pode ser verificado no Tractatus lógicophilosophicus (2001) e nas Investigações filosóficas (1989). Um conceito não é aquilo que é, mas aquilo que está. Em Wittgenstein (1989, p.152), linguagem e conceitos são "instrumentos". No Tractatus, Wittgenstein (2001, p.177) diz que a filosofia é uma atividade e não uma teoria. Wittgenstein (2001, p.263) elucida melhor a questão: "Na filosofia, a questão 'para que usamos propriamente esta palavra, esta proposição?' conduz invariavelmente a iluminações valiosas". Então, faz sentido perguntar o que é um conceito? Trata-se de uma questão interessante que não tem uma solução definitiva e, desde já, ela será direcionada ao conceito-objeto informação na Ciência da Informação.

Epistemologicamente não se tentará direcionar Wittgenstein para a Ciência da Informação. Para analisar a hipótese do progresso dos conceitos na ciência e na filosofia e sua relação com a Ciência da Informação, considera-se a existência de algumas similaridades wittgensteinianas em Kuhn (1989, 2001, 2006). Assim como em Wittgenstein (1989), a preocupação com o conceito parece ser o ponto de partida em Kuhn (2001), mas com algumas diferenças. É importante mencionar a observação feita por Kuhn (2001, p.69) nas Estruturas, limitando a influência de Wittgenstein em suas ideias. Cita-se também a entrevista concedida em 1995, quando Ihe é questionado se ele sabia do uso que faziam Lichtenberg e Wittgenstein do termo "paradigma" quando o empregou pela primeira vez em 1959 no texto "A tensão essencial: tradição e inovação na investigação científica" (Kuhn, 1989, p.280). A resposta de Kuhn (2006, p.360):"Eu certamente não tinha ciência de nenhum dos dois". Nessa mesma entrevista, Kuhn diz: "é tudo linguagem e associo o termo a mudança de valores". A coletânea onde está a entrevista prioriza o estatuto da linguagem nos trabalhos de Kuhn, questão que precisa ser analisada numa perspectiva crítica.

Kuhn $(1989,2001,2006)$ preocupa-se com a educação fornecida pelos esquemas conceituais na ciência normal e com a maneira de transmitir e fazer reconhecer as mudanças das similaridades entre itens justapostos. Parece ter perseguido a hipótese de que a forma de construção e de uso da linguagem poderia determinar mudanças na ciência. Não se trata de uma formulação 
exata nas Estruturas, mas referenciada e explorada por Kuhn em textos posteriores. Os textos "O que são revoluções científicas?" (1987), "Comensurabilidade, comparabilidade, comunicabilidade"(1983),"Mundos possíveis na história da ciência" (1989) e "O caminho desde a estrutura" (1991) compõem a primeira parte do livro "O caminho desde A estrutura" (Kuhn, 2006). Eles são exemplos de como Kuhn vinha "reconcebendo" e acentuando a presença da linguagem nas noções de revoluções científicas, ciência normal, mudança e incomensurabilidade. Como seu objetivo não parece ser o estudo da linguagem na ciência, pelo menos seus principais trabalhos não são indicativos disso, Kuhn se refere à linguagem e seu uso de diversas maneiras: termo, terminologia, vocabulário, léxico, palavra, conceitos, referenciais, discurso e comunidade linguística.

Kuhn (2001) se apropriou e usou o termo e o conceito "jogos de linguagem" para falar dos paradigmas e, especialmente, da incomensurabilidade. Uma apropriação, como diz Kuhn $(2001$, p.69) limitada na falta de esclarecimento do que seria o "mundo" na concepção wittgensteiniana. Assim como as imprecisões em Wittgenstein, a própria concepção de paradigma em Kuhn é nebulosa e imprecisa, porém ela é útil e convergente com os fatos históricos da ciência.

Um paradigma, para Kuhn (2001), é concebido por acordos na comunidade científica, que abandonará o antigo paradigma, adotando o novo como uma espécie de modelo. Porém, a transição de um paradigma para outro não é um acontecimento simples: ela ocorre, geralmente, em movimentos chamados "revolucionários". Por que "revolucionários"? Porque não são modelos no sentido normalizador de uma atividade como, por exemplo, a construção de novos métodos de pesquisa. Um paradigma é uma nova forma de pensar (Kuhn, 2006, p.25). Isto é, antes dos aspectos normativos e de padronização das atividades, é necessário convencer a comunidade científica, onde está ocorrendo uma mudança (anomalia), que seus conceitos já não correspondem à realidade. Quanto mais consistente for o paradigma estabelecido, mais difícil será a transição para um novo paradigma por causa da justaposição da noção de verdade sobre a realidade. Isto ocorre quando as teorias científicas tornam-se consistentes a tal ponto que perdem o elo com a reali- dade. O que antes responderia ao "está assim", agora segue o "é assim". Mudanças revolucionárias transformam termos e referentes, mudam a natureza.

Quando o modelo paradigmático não se assemelha mais à realidade (natureza), ele não progride, pois só serve para descrever e esclarecer a si mesmo, ou seja, seus próprios problemas. Os conceitos se deformam e perdem o sentido. Talvez não seja possível defender a hipótese de que os conceitos perdem o sentido porque não se pode mais dizê-los. Essa hipótese, numa determinada perspectiva, é verificável diante do acordo de que o que não se pode dizer é aquilo que está privado de sentido no outro e na natureza. Também não é preciso recuperar a ideia supostamente nietzschiana do "dizer nada é melhor do que nada dizer", mas esse jogo de palavras, entendido como algo que tem sentido, pode também encerrar o paradoxo da incomensurabilidade dos paradigmas de Kuhn. Quando dizer que um conceito deixou de fazer sentido? Como isso é possível se o conceito ainda é dito? Mesmo para dizer que ele não tem sentido, existe referência de sentido a ele, ou seja, algo que não tem mais sentido. Dessa forma, parece que os paradigmas são substituídos gradualmente quando seus conceitos vão caindo em desuso. Então, os paradigmas revigoram-se na própria linguagem, pois é ela que dá acesso à realidade. O que é possível relacionar das perspectivas de Wittgenstein e Kuhn é o princípio do que está, daquilo que uma comunidade participa sem dizê-lo efetivamente, mas que faz sentido através de suas semelhanças e similaridades. Não é uma enumeração de características. Estas podem ser verificadas no campo normativo, mas os paradigmas não podem ser reduzidos aos campos normativos do discurso científico porque sofrem influências de valores individuais e coletivos.

Na perspectiva dos valores individuais e coletivos, esse tópico será encerrado com um exemplo de Kuhn sobre a autoridade dos paradigmas. Kuhn cita passagens de Charles Darwin e Max Planck. Nas citações, os cientistas registram a frustração de tentar convencer seus pares. Darwin (1889, p.295 apud Kuhn, 2001, p.191) diz:"[...] não espero, de forma alguma, convencer naturalistas experimentados [...] (Mas) encaro com confiança o futuro - os naturalistas jovens que estão surgindo, que serão capazes de examinar ambos os lados da questão com imparcialidade." Já Planck (1949, p.33 apud Kuhn, 2001, p.191) observa que:" [...] uma nova verdade científica não triunfa convencendo seus oponentes e fazendo com que 
vejam a luz, mas porque seus oponentes finalmente morrem e uma nova geração cresce familiarizada com ela". As citações de Darwin e Planck, apesar de descontextualizadas, ilustram as dificuldades de conversão nas comunidades científicas. Apesar de enigmático, psicológico e muito próximo da crença, o termo conversão é usado por Kuhn (2001, p.190) para enfatizar que a transposição de um paradigma a outro não"[...] pode ser feita passo a passo, por imposição da Lógica e de experiências neutras". É preciso acreditar no novo paradigma. Isso, talvez, justifique a preocupação "pedagógica" de Kuhn com o aprendizado científico e sua crítica aos manuais de formação acadêmica.

\section{Conclusão}

No sentido referencial dos manuais, a representação por conceitos é matéria secular no plano do conhecimento. Na Filosofia, suas manifestações encontraram diversas tendências que tentaram explicar sua origem por meio de correntes idealistas, realistas, nominalistas, conceptualistas, empiristas e racionalistas. Muitos foram os filósofos que construíram seus sistemas sobre a natureza dos conceitos e poucos aqueles que conseguiram entendê-la. Dentre aqueles que conseguiram entender essa natureza, diversas tradições foram criadas e tomaram corpo nos campos metafísico, lógico-linguístico, fenomenológico, ontológico e cognitivo. As teses desenvolvidas pela filosofia tiveram acolhida no contexto da ciência moderna e contemporânea. No início, como doutrinas formalizadoras do discurso lógico-científico, depois como depositárias de um intuito desmistificador da linguagem científica universal, determinista e totalitária, mas todas sem um apelo crítico, sem um traço de análise polêmica além da descrição.

\section{Referências}

Abbagnano, N. Dicionário de filosofia. 5.ed. São Paulo: Martins Fontes, 2007.

Bachelard, G. A filosofia do não: filosofia do novo espírito científico. São Paulo: Abril Cultural, 1978. (Os pensadores).

Bachelard, G. A retificação dos conceitos. In: Bachelard, G. Ensaio sobre o conhecimento aproximado. Rio de Janeiro: Contraponto, 2004. p.21-32.
Como elemento de análise crítica, o determinismo conceitual (na filosofia e na ciência) entra em colapso com a constatação de que a verdade é contextual e não absoluta - resultado da aproximação dos conceitos (expressões de verdade) aos contextos de uso e significado da linguagem. Os significados e usos da linguagem passam a quase centralidade nos princípios antideterministas e paradigmáticos. A emergência dos contextos de uso dos conceitos pela linguagem na ciência e na filosofia apresenta características epistemológicas da linguagem e epistêmicas das comunidades onde circulam conceitos, mas não se reduzem a elas. As comunidades de conhecimento não estão isoladas em sua linguagem, pelo contrário, seus conceitos, por vezes, são reconfigurados no campo dos valores, das crenças e da experiência.

Para a Ciência da Informação, as noções de perspectivismo e padrão levantam o contraste entre filosofia e ciência. Além disso, a linguagem é tomada em ambos os aspectos e, por vezes, parece definir-se em campos autônomos. Todos os casos são conhecidos e não levantam polêmicas no momento. Entretanto, observado em maiores detalhes, o contraste entre filosofia e ciência define o modelo de análise do progresso do conceito- objeto da área, no caso a "informação". Se a linguagem natural parece inadequada para a produção de conceitos e se a filosofia não avalia o progresso de seus conceitos, então existe a possibilidade de um progresso através de conceitos científicos. O paradoxo reside no fato de o conceito de informação formar-se e transformar-se a partir de uma "teia" de significados, características, de diversas "fibras" que, aparentemente, participam de um único paradigma, que, por sua vez, reúne, em função da própria natureza participativa, sociocultural e dinâmica do objeto, a "dialetização" do conceito informação entre as linguagens comum, filosófica e científica.

Cassirer, E. Linguagem e conceituação. In: Cassirer, E. Linguagem e mito. 4.ed. São Paulo: Perspectiva, 2003. p.41-62.

Cintra, A.M.M. et al. Conhecimento, informação e linguagem. In: Cintra, A.M.M. et al. Para entender as linguagens documentárias. 2.ed. São Paulo: Polis, 2002. p.19-31.

Ferrater Mora, J. Dicionario de filosofia. 2.ed. São Paulo: Loyola, 2004. v.1. 
Fourez, G. Idealismo e história humana. In: Fourez, G. A construção das ciências: introdução à filosofia e à ética das ciências. São Paulo: Unesp, 1995. p.227-250.

Gil, F. O plano da ciência. In: Deus, J.D. (Org.). A crítica da ciência: sociologia e ideologia da ciência. 2.ed. Rio de Janeiro: Zahar, 1979. p.158-186.

González de Gómez, M.N. A vinculação dos conhecimentos: entre a razão mediada e a razão leve. Liinc em Revista, v.1, n.1, p.16-37, 2005. Disponível em: <http://revista.ibict.br/liinc/ index.php/liinc/article/viewFile/187/104>. Acesso em: 14 set. 2011.

González de Gómez, M.N. Novas fronteiras tecnológicas das ações de informação: questões e abordagens. Ciência da Informação, v.33, n.1, p.55-67, 2004.

Hjelmslev, L. Estudo da linguagem e teoria da linguagem. In: Hjelmslev, L. Prolegômenos a uma teoria da linguagem. 2.ed. São Paulo: Perspectiva, 2006, p.1-5.

Köche, J.C. Problemas, hipóteses e variáveis. In: Köche, J.C. Fundamentos de metodologia científica: teoria da ciência e iniciação à pesquisa. 20.ed. Petrópolis: Vozes, 2002. p.105-119.

Kuhn, T.S. A estrutura das revoluções científicas. 6.ed. São Paulo: Perspectiva, 2001.

Kuhn, T.S. A tensão essencial: tradição e inovação na investigação científica. In: Kuhn, T.S. A tensão essencial. Lisboa: Edições 70, 1989. p.275-291.

Kuhn, T.S. O caminho desde A estrutura: ensaios filosóficos, 1970-1993. São Paulo: Unesp, 2006.

Peirce, C.S. A ética da terminologia. In: Peirce, C.S. Semiótica. 3.ed. São Paulo: Perspectivas, 2005. p.39-43.

Tálamo, M.F.G.M. A pesquisa: recepção da informação e produção do conhecimento. Datagramazero, v.5, n.2, 2004. Disponível em: <http://www.dgz.org.br/abr04/F_I_art.htm>. Acesso em: 25 out. 2012.

Wittgenstein, L. Investigações filosóficas. São Paulo: Nova Cultural, 1989. (Os pensadores).

Wittgenstein, L. Tractatus lógico-philosophicus. 3.ed. São Paulo: Edusp, 2001. 
